\title{
OS DIREITOS HUMANOS, A MULTICULTURALIDADE E O RISCO DO CHOQUE DE CIVILIZAÇÕES: Uma Análise do Mundo Pós-Guerra Fria
}

http://dx.doi.org/10.21527/2176-6622.2019.52.92-105

Recebido em: 25/8/2019

Modificações requeridas em: 1/10/2019

Aceito em: 26/10/2019

Gilmar Antonio Bedin

Doutor em Direito do Estado pela Universidade Federal de Santa Catarina - UFSC. Professor permanente do curso de Graduação em Direito e dos Programas de Pós-Graduação em Direito da Universidade Regional do Noroeste do Estado do Rio Grande do Sul - Unijuí - e da Universidade Regional Integrada - URI Santo Ângelo. http://lattes.cnpq.br/0553982956028307. https://orcid.org/0000-0001-9183-7065 gilmarb@unijui.edu.br

\section{Elenise Felzke Schonardie}

Doutora em Ciências Sociais pela Unisinos. Mestre em Direito pela Unisc. Professora do Programa de Pós- Graduação em Direito - cursos de Mestrado e Doutorado em Direitos Humanos da Universidade Regional do Noroeste do Estado do Rio Grande do Sul - Unijuí. Integrante do Grupo de Pesquisa do CNPq: Direitos Humanos, Governança e Democracia e Direitos Humanos, Justiça Social e Sustentabilidade. Advogada. http://lattes.cnpq.br/0918929438055294. https://orcid.org/0000-0002-9240-5886 elenise.schonardie@unijui.edu.br

Aline Michele Pedron Leves

Mestra pelo Programa de Pós-Graduação Stricto Sensu em Direito - curso de Mestrado em Direitos Humanos da Universidade Regional do Noroeste do Estado do Rio Grande do Sul - Unijuí. Bacharela em Direito pela Unijuí. Integrante do Grupo de Pesquisa do CNPq: Direitos Humanos, Governança e Democracia. Advogada. http://lattes.cnpq.br/9564252232431565. https://orcid.org/0000-0002-0371-5234. alineleves@hotmail.com

\section{RESUMO}

O presente artigo tem como objetivo examinar, no mundo pós-guerra fria, a emergência da globalização e o risco do choque de civilizações daí decorrentes. Partindo do pressuposto de que o direito e a história sempre tiveram algum nível de conexão, nota-se que as transformações após a Segunda Guerra Mundial e os processos resultantes do fenômeno da globalização, tornaram mais evidente essa circunstância e, em consequência, potencializaram os riscos de conflitos de grande intensidade e a violação dos direitos humanos. Nesse sentido, torna-se necessário o questionamento acerca de como é possível superar os impasses, os choques ou os conflitos oriundos das aproximações entre as civilizações de culturas e identidades heterogêneas e, assim, avançar na construção de uma sociedade internacional mais pacífica e coesa. Para tanto, são analisadas, mediante a utilização do método hipotético-dedutivo e da técnica de pesquisa bibliográfica, com aporte teórico-sociológico nas obras de Ulrich Beck e Samuel Huntington, as interseções da sociedade de risco e a interdependência multicultural que se estabelece na nova estrutura da ordem mundial. Com efeito, muitos povos se entrechocam uns com os outros em virtude de suas culturas e ideologias distintas, fato que coloca em xeque os parâmetros da soberania estatal e contribui para que se acentuem os problemas, a fragmentação e o ressurgimento de racismos, nacionalismos e fundamentalismos. Por fim, torna-se necessária a ampliação das iniciativas que fortalecem o diálogo entre as pluralidades culturais existentes e a proteção internacional dos direitos humanos.

Palavras-chave: Direitos humanos. Globalização. Multiculturalidade. Sociedade de risco.

HUMAN RIGHTS, MULTICULTURALITY AND RISK OF THE CLASH OF CIVILIZATIONS: AN ANALYSIS OF THE POST COLD WAR WORLD

\section{ABSTRACT}

This article aims to examine, in the post-Cold War world, the emergence of globalization and the resulting risk of civilization clash. Assuming that law and history always had some level of connection, it can be noted that the transformations after Second World War and processes resulting from the phenomenon of globalization made this circumstance more evident and, consequently, potentiated the risks of intense conflict and the violation of human rights. In this sense, it becomes necessary to question how it is possible to overcome the impasses, shocks or conflicts arising from the approximations between civilizations of cultures and identities heterogeneous and, thus, to advance in the construction of a more peaceful and cohesive international society. Therefore, are analyzed, using the hypothetico-deductive method and the bibliographic research technique, with the theoretical-sociological support in the works of Ulrich Beck and Samuel Huntington, the intersections of the risk society and the multicultural interdependence that is established in the new structure of world order. Indeed, many peoples clash with each other because of their different cultures and ideologies, fact that puts in check the parameters of state sovereignty and contributes to accentuating the problems, fragmentation and resurgence of racisms, nationalisms and fundamentalisms. Finally, it is necessary to expand the initiatives that strengthen the dialogue between the existing pluralities cultural and the international protection of human rights.

Keywords: Human rights. Globalization. Multiculturality. Risk society.

\section{SUMÁRIO}

1 Introdução. 2 A Globalização e a Ampliação dos Riscos. 3 A Emergência de um Cenário Multicivilizacional. 4 A Excessiva Importância do Ocidente. 5 A Nova Configuração do Mundo e a Permanência dos Conflitos. 6 Conclusão. 7 Referências. 


\section{INTRODUÇÃO}

As transformações das últimas décadas foram bastante profundas e geraram grande complexidade política e uma possibilidade concreta de configuração de um verdadeiro choque de civilizações (HUNTINGTON, 2010). Por isso, pode-se afirmar que o fenômeno da globalização se constitui numa referência essencial para a compreensão de um conjunto de transformações nos âmbitos econômico, político, social e cultural que ocorre em todas as regiões do planeta. Em um cenário repleto de modificações, os fatores internos e os externos passam a se confundir e a transcender as fronteiras territoriais, contribuindo para a redefinição das concepções espaço-temporais e corroborando para o crescimento exponencial da complexidade do entorno e da vida humana. Essa conjuntura da contemporaneidade permite a ampliação dos horizontes de possibilidades para as mais distintas culturas que compõem o tecido social e, simultaneamente, indica a emergência de novos desafios mundiais.

Ao mesmo tempo em que a sociedade internacional se configura com base nos benefícios e facilidades resultantes dos avanços dos processos industriais, tecnológicos e científicos da globalização, enfrenta uma série de riscos que anteriormente eram desconhecidos e imprevisíveis, mas que, na atualidade, se encontram plenamente alinhados a esse panorama que se altera permanentemente. Desse modo, a possibilidade de transponibilidade das fronteiras territoriais e das relações de mútua interação entre os povos, tornam-se, até certo ponto, irreversíveis e, por conseguinte, institui-se uma nova ordem mundial, mais institucionalizada e integrada, mas, também, repleta de riscos, conflitos e contradições. Com efeito, o problema central deste artigo reside justamente na questão de como é possível superar os impasses e os choques resultantes das aproximações entre as civilizações de culturas e identidades distintas e, assim, avançar na construção de um mundo mais pacífico e que garanta a proteção internacional dos direitos humanos.

No atual contexto de pluralização dos sujeitos e de relativização das fronteiras territoriais, é inegável a relevância dos direitos humanos. Isso significa afirmar que a combinação das novas realidades, sobretudo no que concerne aos riscos que se predispõe no tecido social e às interações multiculturais entre as civilizações mundiais, reforçou o debate sobre o respeito da proteção dos direitos humanos. Nesse sentido, o presente trabalho analisa, a partir das obras de Ulrich Beck e Samuel Huntington, as transformações ocorridas e suas implicações, com destaque para as abordagens multiculturais e multidisciplinares do tema. Daí, portanto, por meio da utilização do método hipotético-dedutivo e da técnica de pesquisa bibliográfica, o destaque dado se incide na reflexão sobre alguns aspectos fundamentais da sociedade de risco globalizada, sua forma de funcionamento e suas distintas implicações na interdependência civilizacional.

\section{A GLOBALIZAÇÃO E A AMPLIAÇÃO DOS RISCOS}

A conformação de um mundo globalizado impõe um conjunto de desafios. Entre estes, destacam-se a potencialização dos riscos oriundos da modernização, o célere desenvolvimento dos centros de convergência mundial e dos novos processos tecnocientíficos, bem como as mudanças que evidenciam um futuro incerto, efêmero e dotado de liquidez. Em outras palavras, os contornos da contemporaneidade, que se configuram a partir dos densos processos de globalização, resultam, conforme a concepção de Ulrich Beck - que cunhou o conceito da sociedade de risco -, em constantes sentimentos de medo e de incerteza ocasionados pelo surgimento contínuo de novas formas de riscos que ameaçam a proteção universal dos direitos humanos, a paz mundial e as possibilidades de uma maior cooperação entre as nações do globo diante da imprevisibilidade das relações sociais.

Beck (2016, p. 36-37) evidencia, portanto, que a referida sociedade de risco expressa "a acumulação de riscos - ecológicos, financeiros, militares, terroristas, bioquímicos, informacionais - que tem uma presença esmagadora hoje no mundo". Esses riscos caracterizam-se por serem invisíveis, imperceptíveis, escorregadios e de composição futura, possuindo proporções imateriais que escapam à possibilidade de compreensão por meio da ciência. Nessa sociedade de risco ou mesmo de insegurança, consoante Zygmunt Bauman e Ezio Mauro (2016, p. 75), diferentemente "dos perigos antiquados dos períodos anteriores, os riscos que assombram os habitantes da modernidade tardia não são visíveis a olho nu". 
Importa lembrar que, para Beck (2016), risco e perigo não são expressões sinônimas ou equivalentes. O risco ao qual se refere é a ameaça, o contratempo associado a um componente decisório, ou seja, o risco é algo que se corre, é inerente a alguma coisa que se decide enfrentar. O risco está associado a uma probabilidade. O perigo, por sua vez, está associado a toda situação que possui potencial de causar ameaça ou dano, seja em relação a alguém, seja em relação à alguma coisa. Na sociedade de risco não se defende "a ideia de que o mundo contemporâneo é mais arriscado do que as épocas passadas, mas, sim, de que há uma mudança na natureza dos riscos que somos obrigados a enfrentar" (GIDDENS, 2005, p. 538). Na contemporaneidade, o risco provém menos dos perigos ou das ameaças naturais do que das incertezas geradas pelo nosso próprio desenvolvimento social, tecnológico e científico.

O risco tornou-se o elemento central, cotidiano e onipresente em nossas sociedades, e seu controle é o principal aspecto da ordem global. Para Anthony Giddens (2005, p. 74), "os riscos de hoje afetam todos os países e todas as classes sociais. Suas consequências não são meramente pessoais, e sim globais. [...] cruzam as fronteiras nacionais". Tais fatores fazem com que os seres humanos vivam, hoje, em meio a uma constante ansiedade e ameaça de perigos que permeiam a realidade, e que podem, notoriamente, se concretizar em qualquer lugar e momento. Essas sensações, de caráter permanente e difuso, consubstanciam um contexto de medo e insegurança na sociedade de risco globalizada. Importa salientar que o conceito de risco, como afirma Bauman (2008, p. 129), "apreende e transmite a verdadeira novidade inserida na condição humana pela globalização", representando de modo indireto e reafirmando tacitamente "o pressuposto da regularidade essencial do mundo".

Por isso, ao lidar com os riscos, a sociedade confronta-se consigo mesma, uma vez que esses consistem em um produto histórico das civilizações ou, ainda, no reflexo das forças provenientes das ações e omissões dos indivíduos (BECK, 2011, p. 275). Daí, portanto, a atual sociedade, repleta de paradoxos e desafios globais, é, via de consequência, catastrófica, e deve não somente encontrar alternativas para suportar os inúmeros riscos, mas remodelar-se para enfrentar e resolver uma realidade de desastres humanos. Nesse sentido, segundo o entendimento de Eric Hobsbawm (1995, p. 561-562), é bem provável que

[...] a fase atual de colapso pós-Guerra Fria seja temporária. Contudo, esperanças ou temores não são previsões. Sabe-se que, por trás da opaca nuvem de ignorância e da incerteza de resultados detalhados, as forças históricas que moldaram o século continuam a operar. [A humanidade vive] num mundo conquistado, desenraizado e transformado pelo tirânico processo econômico e tecnocientífico do desenvolvimento do capitalismo, que dominou os dois ou três últimos séculos. Sabe-se, ou pelo menos é razoável supor, que ele não pode prosseguir ad infinitum. O futuro não pode ser uma continuação do passado, e há sinais, tanto externamente quanto internamente, de que [a sociedade chegou] a um ponto de crise histórica. As forças geradas pela economia tecnocientífica são agora suficientemente grandes para destruir o meio ambiente, ou seja, as fundações materiais da vida humana. As próprias estruturas das sociedades humanas, incluindo mesmo algumas das fundações sociais da economia capitalista, estão na iminência de ser destruídas pela erosão do que se herdou do passado humano. O mundo corre o risco de explosão e implosão. Tem de mudar.

Nesse panorama, toda a radicalidade e o ritmo dos processos de transformação dos últimos anos trazem à tona os riscos como uma antecipação das catástrofes, os quais dizem respeito, segundo Beck (2016, p. 31), à "possibilidade de acontecimentos e desenvolvimentos futuros, tornando presente um estado do mundo que (ainda) não existe" e com os quais as civilizações podem vir a ser confrontadas em razão dos avanços da industrialização, da ciência e das tecnologias. Assim, a categoria dos riscos refere-se, de um lado, à realidade controversa existente na possibilidade especulativa e, de outro, à catástrofe incidida.

Efetivamente, a soma dos perigos e das inseguranças, sua intensificação ou neutralização recíproca, constitui a dinâmica social e política da sociedade internacional contemporânea, a qual necessita de uma consciência universal de responsabilidade e solidariedade em defesa dos direitos inerentes à humanidade, dentro e fora das fronteiras territoriais dos Estados. Em suma, para Beck (2016, p. 129), "a sociedade de risco mundial promove uma nova lógica histórica", dado que "nenhuma nação pode resolver sozinha" os problemas relacionados à proteção universal dos direitos humanos e à manutenção da paz.

A humanidade, nesse contexto, enfrenta inúmeros riscos de ordem internacional, os quais se encontram articulados irrestritamente na atual sociedade de risco globalizada, com os céleres avanços dos processos técnicos e científicos da modernização. Evidencia-se, pois, que os riscos assumem dimensões globais, 
mas, muitas vezes, podem ocasionar manifestações em âmbito local, com efeitos nocivos, imprevisíveis e, até mesmo, incalculáveis. Esses fatores fazem com que os mecanismos, bem como os instrumentos construídos pela sociedade, tornem-se insuficientes para a identificação e, inclusive, para um verdadeiro controle das inseguranças que afligem a realidade do mundo contemporâneo.

Por esse motivo, com o reconhecimento dos riscos como resultado histórico das civilizações, o Estado de bem-estar social, a segurança coletiva e os direitos humanos restam ameaçados. Isso acontece porque os riscos, envoltos no panorama da sociedade globalizada, não são alternativas capazes de oportunizar uma escolha ou rejeição no curso do debate sociopolítico. Ademais, se anteriormente ao mundo atual os riscos implicavam inúmeras fatalidades, na era global eles passam a adquirir um sentido mais profundo, ou seja, surgem como uma ameaça que, conforme afirma Beck (2016, p. 32), "determina as nossas expectativas, ocupa as nossas cabeças e orienta a nossa ação", transformando-se em uma "força política que muda o mundo". Diante disso, os riscos globais consistem-se, hoje, nos principais motivos desencadeadores das transformações explosivas

[...] através da qual os contornos da sociedade do século XXI se tornam visíveis. A teoria da sociedade de risco mundial ocupa-se da onipresença crescente de uma incerteza criada à escala global. As instituições básicas, os agentes da Primeira Modernidade, cuja tarefa consiste em avaliar e controlar as incertezas criadas, são minadas pela consciência crescente da sua própria ineficiência, se não mesmo do caráter contraproducente das suas medidas. Tal não acontece de forma desorganizada, mas sim sistemática. A radicalização da Modernidade realça esta ironia do risco: as ciências, o Estado e as forças armadas tornam-se parte do problema que deviam resolver. É este o significado da expressão "modernidade reflexiva": não se vive em um mundo pós-moderno, mas num mundo mais moderno. Não é a crise, mas sim a vitória da Modernidade (BECK, 2016, p. 110-111, grifo do autor ).

À vista desse cenário de modificações oriundas dos processos da globalização, emerge a necessidade de se encontrar outras maneiras para compreender o mundo atual, posto que novos conflitos e riscos passam a integrar a vida cotidiana dos indivíduos e, inclusive, as estruturas de governança mundial. Todas as crises e incertezas que acompanham o processo histórico-social tornam o mundo cada vez mais inseguro e ávido por tentar construir novas formas de cooperação internacional. Nesse sentido, a demanda por novos instrumentos e por iniciativas sem precedentes é considerada fundamental para a compreensão do mundo em transformação e sua configuração como uma nova era.

Essa nova era caracteriza-se por ser tardia, reflexiva, globalizada e radicalizada, que conecta os indivíduos em uma mesma experiência mundial, a qual distribui e socializa os riscos das civilizações dentro e fora das soberanias estatais, ou seja, em âmbito transnacional. Logo, as grandes inovações e os impactos dos processos tecnocientíficos, que possibilitaram uma nova conformação do mundo, com aspectos positivos e negativos, somam-se à dissolução das fronteiras geopolíticas, à cooperação planetária para o estabelecimento de ações coordenadas capazes de evitar o risco do choque de civilizações e aos anseios pelo fortalecimento dos direitos humanos e do respeito às heterogeneidades culturais no seio da sociedade globalizada.

\section{A EMERGÊNCIA DE UM CENÁRIO MULTICIVILIZACIONAL}

Foi justamente por meio dos desafios emergentes no final do século 20 que se intensificou a efervescência das transformações da nova era que se configurava mundialmente, marcada pela relativização da soberania dos Estados modernos, pela possibilidade de transponibilidade das fronteiras territoriais e por uma maior interdependência entre as nações do globo. Em diferentes contextos, pode-se afirmar que as relações históricas e culturais que intervêm nos processos da sociedade global vêm demonstrando que estas já não são suficientes para explicar a complexidade das interações entre os atores políticos, econômicos e sociais que se cristalizam nos albores do novo milênio.

Nesse panorama contemporâneo de interconexões que se consolidam diante dos paradigmas e paradoxos provenientes dos processos da globalização do mundo, os mecanismos e as vertentes pragmáticas da sociedade fundamentam-se, sobretudo, nos pilares das forças ideológicas de poder, na tecnologia informacional 
e nos interesses econômicos, distanciando-se, cada vez mais, dos valores humanistas e universais. Além de ser um fenômeno revolucionário na contemporaneidade, a globalização desafia, essencialmente, as formas tradicionais que produzem a condição ou o sentimento de pertença e as identidades ${ }^{1}$ culturais.

No mundo globalizado pós-Guerra Fria (1991), conforme Samuel Huntington (2010, p. 22), "pela primeira vez na História, a política mundial se tornou multipolar e multicivilizacional". Notadamente, durante a maior parte da existência humana as interações entre as civilizações foram praticamente intermitentes ou, até mesmo, inexistentes. Perpassado o primeiro período do sistema internacional multipolar - caracterizado pela presença dos grandes impérios, pelas conquistas e colonizações de territórios, bem como pelas devastadoras guerras mundiais - e a mais duradoura época em que a política planetária constituiu-se como bipolar - na qual as civilizações eram lideradas, de um lado, pelas ideologias capitalistas norte-americanas e, de outro, pelas ideologias socialistas soviéticas -, nota-se que as distinções entre os povos não se perfaziam apenas em patamares ideológicos, econômicos ou políticos. Muito pelo contrário, elas se sobressaíam pelo drástico afastamento cultural que se demonstrava como característico no âmbito da sociedade de risco globalizada.

É evidente que um dos riscos, e, talvez, o mais proeminente que advém da globalização do mundo atual, consiste no choque das civilizações já consolidadas no final do século 20, haja vista que este impacto inevitável e resultante do incremento da multiculturalidade configura-se, como afirma Samuel Huntington (2010, p. 14), "na maior ameaça à paz mundial", até porque é plenamente inegável que "uma ordem internacional baseada nas civilizações consiste na melhor salvaguarda contra a guerra mundial". O novo período da história contemporânea requer, então, uma série de novas perspectivas e escala de valores, pois, o significativo desenvolvimento das relações comerciais, o amplo estímulo da indústria cultural e o incremento das inovações tecnológicas e científicas, proporcionaram uma contundente expansão das culturas para além das fronteiras estatais e, por conseguinte, inauguraram novos padrões que inspiram as tendências universalistas a partir de uma postura globalizante.

Pode-se afirmar, então, que foi em virtude dos progressos sobrevindos dos processos da globalização do mundo que a humanidade se aproximou, independentemente do lugar no qual se situam os indivíduos. Nesse sentido, lembra Milton Santos (2017, p. 172) que "o próprio mundo se instala nos lugares", essencialmente "pela presença maciça da humanidade misturada, vinda de todos os quadrantes e trazendo consigo interpretações variadas e múltiplas" que se entrechocam e cooperam para "a produção renovada do entendimento e da crítica da existência". Esses novos padrões culturais em escala planetária, no entanto, não conseguiram suprimir os modelos peculiares dos povos e a raiz primordial das relações internacionais, que continuaram a residir no seio das sociedades nacionais. Ainda assim, foram considerados fundamentais para remodelar a consciência a respeito do que é ser do mundo e estar no mundo, conforme os anseios dessa nova era globalizada.

Mesmo que o progresso seja capaz de possibilitar, de certo modo, uma maior integração das sociedades internas dos Estados em uma sociedade global ou transnacional, os choques civilizacionais são consequências que não podem ser evitadas ante a conformação da nova ordem do mundo contemporâneo, isso porque as heterogeneidades culturais são múltiplas e profusamente perceptíveis. Nesse contexto, à medida que o paradigma clássico, fundado nas reflexões acerca da sociedade nacional, foi sendo subsumido gradativamente por um novo modelo, amparado nas ponderações que analisam a sociedade de risco globalizada, surgem inúmeros conflitos que se contrapõem aos pressupostos homogeneizantes. Ao mesmo tempo em que as heterogeneidades culturais das civilizações se chocam, contudo, elas também contribuem para uma produção da compreensão acerca da existência humana, quando o cotidiano de um indivíduo enriquece, simultaneamente, o do outro (IANNI, 2013, p. 239; IANNI, 2014, p. 12-81; LUCAS, 2013, p. 166; SANTOS JUNIOR, 2007, p. 78).

Consolida-se, então, um novo mundo. De acordo com Milton Santos (2017, p. 173, grifo do autor), o que, afinal, "se cria é o mundo como realidade histórica unitária, ainda que ele seja extremamente diversificado". Isso pressupõe que, na medida em que o mercado global de efeitos avassaladores se constitui como capaz de acarretar a homogeneização do planeta, as diferenças entre as culturas locais passam a ser aprofun-

\footnotetext{
A identidade sempre relaciona-se com a cultura. Por isso, a identidade cultural consiste em um processo, em uma invenção dialética e dinâmica, capaz de evidenciar o posicionamento específico dos seres humanos no mundo e definir as especificidades coletivas. Além disso, a identidade é caracterizada pela diferença, uma vez que essa apenas pode ser percebida quando comparada ou relacionada com outras culturas (LUCAS, 2013, p. 165).
} 
dadas. É justamente por isso que a mundialização cultural se institui como uma verdadeira reação aos efeitos perversos do fenômeno da globalização, pois, ao invés de se sustentar em um modelo flexível que não vise a homogeneidade e a assimilação, possibilita uma articulação reacionária que valoriza as culturas sempre que se contrapõe às forças do mercado global.

Desse modo, as transfigurações que ocorrem na sociedade internacional, em especial a desterritorialização produzida pela possível dissolução das fronteiras territoriais, fragilizam os espaços privilegiados e exclusivos de determinada cultura, o que promove uma verdadeira deslocalização das relações sociais que perdem a força enraizadora do seu entorno físico e, por conseguinte, assumem contornos mais abstratos. Segundo Lucas (2013, p. 167), portanto, "torna-se cada vez mais difícil definir os limites de cada povo e de cada cultura e aqueles entendimentos lastreados em conceitos como 'os de fora' e 'os de dentro', estrangeiro e nacional, tendem a ser substancialmente relativizados".

Além do mais, há controvérsias que são engendradas pela globalização em todas os âmbitos da sociabilidade contemporânea. Acerca disso, Octavio lanni (2014, p. 28) afirma que as ações empenhadas na sociedade global "provocam forças adversas, novas, antigas, atuais e anacrônicas, recriando e multiplicando articulações e tensões". Nesse contexto, ainda que o local e o global não se excluam mutuamente e se interpenetram no que concerne à (re)estruturação espacial, social, política e institucional, não é possível afirmar que a globalização do mundo gera somente fragmentações, isso porque as novas conexões se constituem como indispensáveis para as relações de interdependência mundial.

O que se percebe, portanto, é que os processos de interconexão entre as culturas, os indivíduos e os locais se transnacionalizam e, consequentemente, modificam o cotidiano da vida em sociedade em razão da desterritorialização. Então, quando caem por terra as antigas concepções de tempo e de espaço, pluralizadas pelo mundo afora - isso em virtude das aproximações proporcionadas pelas novas tecnologias, pelas redes de transporte e de informação -, tanto o local quanto o global não podem mais ser compreendidos de forma autônoma e isolada, pois, nas palavras de Beck (1999, p. 139), "em todos os lugares, a ideia de que se vive num lugar isolado e separado de todo o resto vai se tornando claramente fictícia". Ainda, conforme preceitua o referido autor,

[...] a globalização - que afinal nunca deixa os globalizadores globalizados se globalizarem globalmente [...] impõe uma nova sociologia do local. O local é redescoberto, porém não [...] em sua antiga estrutura, que o encapsula e aparta do mundo, e sim como ponto nodal da rede global. [...] Não há possibilidade de retorno às idealizadas comunidades isoladas e homogeneizadas, fechadas para o exterior. A exigência de abertura da localidade para o mundo não é uma fantasia, é uma realidade global que, no entanto, tampouco deve ser idealizada (BECK, 2003, p. 184-185).

Nessa conjuntura da nova ordem mundial estabelecida em decorrência de uma série de fatores, dentre estes o fim da bipolaridade entre capitalismo e socialismo, verifica-se uma unificação entre o local e o global. Na mesma esteira de pensamento, lanni $(2014$, p. 97) afirma que desde que a sociedade de risco globalizada passa a se caracterizar como uma verdadeira "realidade histórica, geográfica, econômica, política e cultural, modifica-se o contraponto parte e todo, singular e universal". Apesar, no entanto, da notável aproximação provada pela globalização, as diferenças culturais continuam presentes, não mais de uma forma isolada, mas, sim, misturadas e interdependentes no tecido social.

Desse encontro de identidades plurais deriva um conjunto de ruídos ou riscos, isto é, as divergências sobressaem-se e o choque entre as civilizações, que antes viviam separadamente, se acentua e desafia o cenário do mundo contemporâneo, cuja sociedade internacional precisa encontrar mecanismos capazes de gerir os conflitos e as estranhezas provocadas por uma mescla de fatores complexos - tais como as migrações em massa, o terrorismo, as disputas pelo poder e acúmulo de capital, a proliferação nuclear, a democracia e os direitos humanos - que se se estabelecem, com notoriedade, frente aos mais diversos contrastes multiculturais. No pós-guerra fria, de acordo com Huntington (2010, p. 43), "os Estados cada vez mais definem os seus interesses em termos civilizacionais"; isso significa que as nações do globo "cooperam e se aliam com os Estados que têm culturas semelhantes ou em comum e entram em conflito com maior frequência com países de culturas diferentes". É evidente, portanto, que as intenções e as relações estatais são surpreendentemente instituídas conforme considerações de caráter socialmente cultural. 


\section{A EXCESSIVA IMPORTÂNCIA DO OCIDENTE}

O momento de euforia que se estabeleceu com o fim do conflito Leste-Oeste acarretou uma verdadeira ilusão de harmonia, à medida que muitos acreditavam que o marco final das evoluções ideológicas da humanidade contribuiria com a universalização democrática liberal do Ocidente. Mesmo com a queda do Muro de Berlim (1989), no entanto, o desmoronamento dos regimes socialistas (1991) e o triunfo da democracia liberal, a ausência de conflitos e a harmonia global, não passaram de uma grande ilusão. De fato, o mundo se (re)configurou de uma forma bastante distinta no início da década de 90 , entretanto, ainda que as mudanças fossem inevitáveis, o final do século 20 não foi, necessariamente, o mais pacífico. Os novos paradigmas da política mundial ajustaram-se de acordo com os mais diversos patamares culturais e civilizacionais, os quais contribuem para a emergência de uma série de desafios relativos aos múltiplos aspectos da sociedade propriamente globalizada, a qual rege a maneira com que se constroem as nações do planeta.

Por isso, os conflitos mais irrestritos, relevantes e temerosos não se instituíram, e tampouco ocorrerão entre as classes sociais - ricos e pobres - ou entre os demais grupos estipulados em termos econômicos, mas, sim, entre os povos pertencentes às mais distintas identidades culturais. Desse modo, os choques das dissemelhanças nacionais são capazes de produzir um conjunto de guerras tribais e de conflitos étnicos no seio de qualquer uma das civilizações mundiais (HUNTINGTON, 2010, p. 24-37; IANNI, 2014, p. 95; SASSEN, 2010, p. 38). Além disso, a tendência de pensar acerca da existência de dois mundos vem sendo constantemente repetida em esfera social, posto que as pessoas ficam sempre tentadas a dividir

[...] os povos em nós e eles, o grupo que está na onda e o outro, nossa civilização e aqueles bárbaros. Os estudiosos analisaram o mundo em termos de Oriente e Ocidente, Norte e Sul, centro e periferia. Os muçulmanos tradicionalmente dividem o mundo em Dar al-Islam e Dar al-Harb, o reino da paz e o reino da guerra. Essa distinção se refletiu - e, num certo sentido, se inverteu - ao fim da Guerra Fria por estudiosos norte-americanos que dividiram o mundo em "zonas de paz" e "zonas de agitação". As primeiras abrangiam o Ocidente e o Japão, com cerca de 15 por cento da população mundial, e as últimas compreendiam todos os demais (HUNTINGTON, 2010, p. 39).

Com efeito, a predominância do poderoso sistema de economia capitalista, do contratualismo político estatal e da ideologia liberalista como a única sustentável no mundo multipolar pós-guerra fria, fez da última onda da globalização e de todo o avanço tecnológico, científico e informacional, conforme pressupõe José Eduardo Faria (2002, p. 52-55), uma clara tentativa de ocidentalização mundial, que se originou na Europa e foi revigorada nos Estados Unidos, expandindo-se pelos "países e continentes, em surtos sucessivos e frequentemente contraditórios" (IANNI, 2002, p. 71). A ideia de ocidentalização do mundo já havia sido prevista por Georg Hegel (2005) e sopesada por Karl Marx (2008) ainda no século 19, entretanto foi largamente desenvolvida, a partir do decurso do século 20, por teóricos como Max Weber (2013), em razão da ascensão do capitalismo e, na sequência, pela emergência esmagadora do fenômeno da globalização.

Desde o término da Segunda Guerra Mundial, os Estados empenharam-se em compreender as condições, as vantagens e as desvantagens da ocidentalização, preocupando-se com o desenvolvimento, os avanços da modernização, a urbanização, a industrialização, as relações de dependência e o imperialismo, bem como em relação às distinções entre centro e periferia. Pouco a pouco, conforme lanni (2002, p. 73), "todos os lugares, regiões, países, continentes, a despeito das diferenças socioculturais que lhes são próprias, os indivíduos e as coletividades [passam a ser] movidos pela mercadoria, mercado, dinheiro, capital, produtividade, lucratividade", sendo amplamente influenciados pela orientação das diversas organizações multilaterais e das empresas transnacionais.

Foi com a dissolução da União das Repúblicas Socialistas Soviéticas (URSS), em 1991, que o Ocidente triunfou, ao ver ser afastado o seu desafiante mais poderoso do predecessor período bipolar. Como consequência, o mundo passou a ser moldado de acordo com os objetivos, interesses e prioridades dos principais países ocidentais, os quais admitiam uma participação ocasional do Japão. Nesse contexto, os Estados Unidos da América (EUA) assumiram a condição de ser a única superpotência mundial, atuando em conjunto com o Reino Unido e a França para decidirem as questões cruciais relacionadas às políticas de manutenção da paz e 
da segurança internacionais; como também, juntamente com a Alemanha e o Japão, a potência norte-americana passou a tomar um conjunto de decisões concernentes aos assuntos de ordem econômica (HUNTINGTON, 2010, p. 125).

Por isso, é possível perceber que o Ocidente tem importância fundamental no mundo atual. Essa significância revela-se em vários fatores: a) dominam os mercados internacionais de capitais; b) são donas e operadoras do sistema bancário mundial; c) controlam o sistema monetário internacional; d) constituem-se como os principais clientes do mundo; e) fornecem a maioria dos bens de consumo; f) exercem controle sobre as principais rotas marítimas do mundo; g) desenvolvem a maior parte das pesquisas científicas e das tecnologias de ponta; h) dominam o acesso ao espaço e a indústria aeroespacial; i) regem as redes de comunicação e informação internacionais; j) controlam a indústria bélica que produz armamentos de alta tecnologia; k) são capazes de realizar intervenções militares maciças; e l) exercem uma grande liderança e influência moral dentro de diversas sociedades (HUNTINGTON, 2010, p. 125).

Todos esses fatores são fundamentais e revelam a excessiva presença do Ocidente na atual sociedade internacional. De fato, na atualidade, a ocidentalização, que é ao mesmo tempo social, econômica, política e cultural, desenvolve-se de formas díspares, articuladas e desencontradas. Esse fato somente é contrabalançado pela rápida emergência econômica e política da Ásia (em especial, da China). De qualquer forma, a hegemonia do Ocidente deixa evidente a grande desigualdade existente e explica o desenvolvimento paradoxal, de um lado, de uma crescente interdependência mundial e, de outro, a existência de uma grande tensão e de um conjunto de conflitos e contradições, tanto em âmbito nacional quanto internacional. Esse fato, contudo, não impede a unificação mundial como resultado da globalização, haja vista que as aproximações decorrentes da desterritorialização e da compreensão acerca do tempo e do espaço trazem à tona os efeitos que acentuam as diferenças em âmbito social e que, simultaneamente, aumentam o clima de tensão e de disputa entre os povos (IANNI, 2002, p. 49; LUCAS, 2013, p. 179).

Daí, portanto, faz sentido a afirmação de Zygmunt Bauman $(1999$, p. 6) de que a globalização do mundo "tanto divide como une; divide enquanto une - e as causas da divisão são idênticas às que promovem a uniformidade do globo", isso porque, juntamente com as "dimensões planetárias dos negócios, das finanças, do comércio e do fluxo de informação, é colocado em movimento um processo 'localizador', de fixação no espaço". Ambos os processos, globalização e localização, estão intimamente relacionados e se diferenciam nos mais variados segmentos civilizacionais, contribuindo com as desigualdades e com a estratificação de uma época pós-moderna, quando o mundo ocidental se apresenta com uma hegemonia de caráter neoimperial bastante intenso. Apesar disso, lembra Huntington (2010, p. 122) que esse cenário pode ser alterado e que a modernização da era global não significa, necessariamente, ocidentalização, pois, "as sociedades não ocidentais podem se modernizar, e têm se modernizado, sem abandonar suas próprias culturas e sem adotar de forma generalizada os valores, as instituições e as práticas ocidentais".

Isso, entretanto, não pode ser considerado algo simples. É que, ao final do século 20 , a cultura também representou, concomitantemente, uma força que unifica e divide. Cabe observar que muitos povos se separam em virtude das ideologias, mas se unem pela cultura semelhante - como no caso das duas Alemanha pós-1989 e, inclusive, como vem acontecendo com as duas Coreias e com a China. Já as sociedades que se aproximam pelas ideologias ou circunstancias históricas se dividem, no entanto, em virtude das divergências culturais da civilização - como ocorreu na União Soviética, na lugoslávia e na Bósnia - e, além disso, restam sujeitas a tensões intensas - a exemplo da Ucrânia, Índia, Nigéria, Sudão, Siri Lanka, dentre outros Estados nacionais. Logo, percebe-se que os países que possuem afinidades culturais conseguem cooperar tanto em termos políticos quanto econômicos.

Diante disso, a história das relações internacionais contemporâneas vem demonstrando que as organizações mundiais que instituem seus pilares básicos nas nações que detêm aspectos culturais comuns, apresentam mais êxito em sua atuação quando comparadas às entidades que ousam transcender as identidades das culturas locais. Nesse sentido, o Ocidente possui uma grande vantagem. Isso verifica-se no fato de que não é possível negar, então, que a política mundial vem sendo cada vez mais influenciada pelas organizações internacionais, estando nela presentes muitos dos valores tidos como ocidentais. É evidente, entretanto, que isso não impede que as mesmas fortaleçam a emergência de uma sociedade multicêntrica e multicultural, 
apontando para a impossibilidade da criação de um império global, tendo em vista o surgimento de outras potências em todas as áreas do mundo, que rompem com supremacia norte-americana (HUNTINGTON, 2010, p. 25; LUCAS, 2013, p. 181).

Em um contexto em que a diversidade cultural se institui de forma bastante emblemática e, até mesmo, relativamente profética, verifica-se que a ascensão expressiva de novas potências mundiais vem contribuindo com a progressiva perda da hegemonia do Ocidente, a exemplo da China, ${ }^{2}$ dos "velhos tigres asiáticos" (Taiwan, Coreia do Sul, Hong Kong e Cingapura), bem como dos "novos" de economias emergentes (Filipinas, Tailândia, Malásia, Indonésia e Vietnã). Além disso, merecem ser destacados também os Estados do Catar, Kuwait e Emirados Árabes Unidos (EAU), localizados no Oriente Médio, os quais se sobressaem pela forte economia de exportação de petróleo e gás natural. Ressalta-se, ainda, a atuação da Rússia, que reemerge no contexto pós-guerra fria como a nação detentora da maior reserva nacional de gás natural do mundo, bastante influente na exploração de suas grandes reservas de petróleo e dos setores industriais bélico, nuclear e aeroespacial. Também, salienta-se a ampla atuação do Brasil, Índia, África do Sul e demais países que surgem como potências emergentes ${ }^{3}$ no âmbito das relações econômicas Norte-Sul.

Diante disso, o Ocidente perde parte de sua importância e o mundo torna-se muito mais diversificado e plural. Esse fato confirma os argumentos de Samuel Huntington na medida em que afirmou ser inconcebível pensar que a modernização, oriunda da globalização econômica e do triunfo civilizatório, "levaria ao fim da pluralidade das culturas históricas corporificadas durante séculos nas grandes civilizações do mundo". Ao contrário, sustenta o referido autor, o que se verifica é justamente que "a modernização reforça as outras culturas e reduz o poder relativo do Ocidente", isto é, a nova ordem mundial caracteriza-se como mais moderna e menos ocidental (HUNTINGTON, 2010, p. 122).

Desse modo, cabe observar que as identidades culturais, inclusive as periféricas, passam a ter influência e a modificar o cenário da sociedade globalizada em defesa das diferenças multiculturais perante os anseios dos ideais de uma homogeneização que não se concretiza mundialmente. É bem verdade, no entanto, que as aproximações possibilitadas pela globalização fazem com que as mais distintas culturas se entrecruzem, disputando, frequentemente, os mesmos espaços e, até mesmo, refutando-se mutuamente "como forma de estabelecer sua retórica de exclusão e inclusão a partir da afirmação de sua identidade" (LUCAS, 2013, p. 180). À medida que o globalismo ocidental carrega consigo as tendências da homogeneização, acentua também os problemas sociais, coloca em xeque os parâmetros modernos da soberania dos Estados e contribui com a fragmentação e o ressurgimento de localismos, racismos, nacionalismos e fundamentalismos (IANNI, 2014, p. 191). Ainda sobre o declínio do poder político, econômico e militar da civilização ocidental, deve-se observar que:

\footnotetext{
Para os economistas Jose Gabriel Porcile Meirelles e Wellington Pereira (2008, p. 19-21), a ascensão econômica da China possui um lugar de destaque, sobretudo no comércio mundial. Esse fato consistiu em uma das mudanças mais significativas e relevantes das últimas décadas do século 20 e início do 21, haja vista que foram redefinidas as modalidades e as intensidades dos fluxos comerciais e de investimentos em âmbito global. Sem dúvida, é inegável "a rapidez com que a China se transformou num ator de primeira linha no comércio mundial", multiplicando "por oito sua participação nas exportações no total dos setores (embora partindo de um patamar muito baixo) entre 1985 e 2003, e alcançou valores superiores a $20 \%$ no caso dos setores de baixa tecnologia." (MEIRELLES; PEREIRA, 2008, p. 19-21). Além disso, ao analisar um conjunto de dados estatísticos divulgados pelo Banco Mundial, o economista José Eduardo Cassiolato (2013, p. 78), em uma tentativa de avaliar os resultados das estratégias político-econômicas chinesas, constatou que "a porcentagem de produtos de alta tecnologia, no total de manufaturados exportados, aumentou vertiginosamente: passou de aproximadamente $5 \%$, em 1990 para algo em torno de 30\%, em 2011". Esse amplo crescimento do poder econômico e da influência geopolítica fez da China a maior nação importadora de commodities e exportadora mundial de tecnologias informacionais e comunicacionais, o que levou até mesmo "os Estados Unidos a dificultarem a entrada em seu mercado dos bens de origem chinesa". De fato, as políticas nacionais implementadas na China vêm surtindo efeitos expressivos, trazendo à tona o prognóstico de que "se os objetivos traçados pelo Estado chinês forem alcançados, em 2050, a China deverá se tornar líder tecnológica mundial" (CASSIOLATO, 2013, p. 78). Por fim, apesar da significativa desigualdade socioeconômica, a China já se classifica como uma das maiores potências econômicas do mundo.

3 As principais potências econômicas emergentes do mundo constituem o grupo político de cooperação Brics: Brasil, Rússia, Índia, China e África do Sul, que se reúnem anualmente e, desde a sua primeira cúpula, no ano de 2009, vêm expandindo expressivamente o seu conjunto de atividades nos âmbitos da coordenação da governança política e da cooperação de governança econômico-financeira e multissetorial (ITAMARATY, 2019).
} 
A vitória do Ocidente na Guerra Fria produziu não um triunfo, mas a exaustão. O Ocidente está cada vez mais preocupado com seus problemas e necessidades internos, ao mesmo tempo em que enfrenta um lento crescimento econômico, o desemprego, enormes déficits públicos, uma ética de trabalho em declínio, baixas taxas de poupança e, em muitos países, inclusive nos Estados Unidos, a desintegração social, drogas e criminalidade. O poder econômico está se deslocando rapidamente para a Ásia Oriental e o poder militar e a influência política estão começando a ir pelo mesmo caminho. A Índia está na iminência de uma decolagem econômica e o mundo islâmico está cada vez mais hostil para com o Ocidente. Está se evaporando rapidamente a disposição de outras sociedades de aceitar os ditames do Ocidente ou de acatar seus sermões, bem como a autoconfiança e a vontade de dominar o Ocidente (HUNTINGTON, 2010, p. 126-127).

Nesse panorama, surge o seguinte questionamento: o Ocidente ocupa, realmente, um lugar de destaque ou de declínio no mundo contemporâneo? Talvez a resposta mais precisa para essa pergunta seja: ambos. Isso se deve ao fato de que o mundo ocidental ainda possui um predomínio muito amplo na sociedade internacional e, provavelmente, continuará tendo poder e influência por um longo período no século 21 . É evidente, contudo, que um somatório de transformações graduais, inevitáveis e fundamentais tem influenciado os equilíbrios de poderes entre as mais distintas civilizações do globo, ressaltando que o poderio do Ocidente permanecerá em declínio. Enquanto a supremacia ocidental se decompõe, grande parte do seu poder irá se esvair ou simplesmente ser difundido entre outras civilizações principais. É plenamente verificável que uma expansão significativa do poder de influência mundial vem ocorrendo, sobretudo, nas civilizações asiáticas, "com a China emergindo gradualmente como a sociedade com maior probabilidade de desafiar o Ocidente" (HUNTINGTON, 2010, p. 128).

\section{A NOVA CONFIGURAÇÃO DO MUNDO E A PERMANÊNCIA DOS CONFLITOS}

A perda da importância do Ocidente é um fato muito importante e que abre novas possibilidades. É que, como lembra Arjun Appadurai (1990, p. 295), um dos problemas centrais do mundo global atual reside na "tensão entre a homogeneização e a heterogeneização cultural". ${ }^{4}$ Nesse sentido, as pluralidades culturais, que transcendem as fronteiras estatais, ampliam as tensões e, por conseguinte, induzem a afirmação dos particularismos. Pode-se afirmar, então, que a defesa das diferenças ganha força no panorama global, enquanto estas reivindicam, cada vez mais, reconhecimento. Assim, se coloca a questão de como é possível compatibilizar esse paradoxo complexo.

Talvez, a saída esteja na afirmação de uma única civilização global plural. Esse fato confirmaria a possibilidade indicada por Samuel Huntington (2010, p. 57-58) de que deve ser uma "entidade cultural mais ampla", na qual fazem parte "as aldeias, as religiões, os grupos étnicos, as nacionalidades e os grupos religiosos" que possuem "culturas distintas em diferentes níveis de heterogeneidade". Desse modo, é bem verdade que as identidades culturais se constituem pelas diferenças e estranhamentos provocados nos encontros sociais. Se Huntington (2010, p. 62-66) divide o mundo em oito ${ }^{5}$ grandes civilizações - Sínica, Japonesa, Hindu, Islâmica, Ortodoxa, Ocidental, Latino-americana e Africana -, frequentemente as culturas dessas comunidades, que compõem a pluralidade do entorno, chocam-se em relação às próprias individualidades. Acerca disso, nota-se que tanto a cultura quanto as identidades civilizacionais delineiam os padrões coesivos e desintegrativos no âmbito de uma sociabilidade que se globalizou, bem como os inúmeros conflitos que emergem na ordem mundial, com suas tensões e articulações, contradições e perspectivas, próprias do fim do século 20.

O cenário das décadas de 80 e 90 do século 20, foi marcado pela soma dos problemas raciais e culturais. Esses impasses estavam inseridos, profundamente, no seio das guerras e revoluções, nas lutas sociais em busca da descolonização, nos ciclos expansivos e recessivos das economias, nas migrações, nos movimentos da força de trabalho, dentre outros mais ou menos notáveis na perspectiva histórica-social do século passa-

\footnotetext{
Tradução nossa. Texto original: "[...] the central problem today's global interaction is the tension between cultural homogenization and cultural heterogenization".

5 Essa divisão do mundo, realizada por Samuel Huntington, padece de elementos mais elucidativos, isso porque o cientista político norte-americano separa, até mesmo, as civilizações de países que possuem padrões de sociabilidade cultural bastante semelhantes. A exemplo disso, não faz muito sentido desassociar, em civilizações diferentes, a Europa da América Latina e, inclusive, dos Estados Unidos, uma vez que as nações latino-americanas foram colonizadas pelas comunidades europeias e apresentam uma influência ocidental norte-americana bastante intensa no âmbito da cultura civilizacional.
} 
do. Cabe observar que a expansão das demandas culturais advém da ampla convivência relacional oriunda da globalização, contexto no qual os contornos das diferenças passam a ser expostos e as vulnerabilidades intensificam-se diante dos estranhamentos que exigem uma profunda reflexão acerca das noções de interno e externo, as quais disputam, em um mesmo espaço, por igual reconhecimento.

Como já foi referido anteriormente, os diversos conflitos que surgem nesse contexto são oriundos das adversidades étnicas ou raciais que se desenvolvem no jogo das forças sociais, compreendendo consequências políticas, econômicas e culturais em esfera local, regional, nacional e, por vezes, mundial (IANNI, 2014, p. 151; LUCAS, 2013, p. 183). De fato, não existem possibilidades para escapar das tensões existentes - que se caracterizam de maneiras distintas e com múltiplos graus de intensidade -, pois, na sociedade de risco globalizada, repleta de heterogeneidades, as reivindicações em busca do respeito à igualdade e à diferença eclodem em todos os lugares do mundo. Nessa mesma perspectiva, Ulrich Beck $(2016$, p. 114) evidencia que a chamada sociedade de risco

[...] exige um olhar sobre a pluralidade do mundo, que o olhar nacional poderia ignorar. Os riscos globais criam um espaço moral e político capaz de dar origem a uma cultura civil de responsabilidade que pode transcender fronteiras e contradições. A experiência traumática da vulnerabilidade de todos e a responsabilidade pelos outros, daí resultante, também em nome da própria sobrevivência, constituem as duas faces da crença no risco mundial [...] que cria novos espaços de ação.

Por tais razões, Huntington (2010, p. 405-408) defende que "a segurança mundial requer a aceitação da multiculturalidade global", haja vista que em todas as civilizações de culturas distintas existem disposições universais, e é justamente por isso que os requisitos necessários "para a coexistência cultural exigem uma busca do que é comum à maioria das civilizações. Num mundo multicivilizacional, o caminho construtivo reside em [...] aceitar a diversidade e buscar os aspectos em comum". Com efeito, a própria cultura consegue encontrar os horizontes da universalização e, ao mesmo tempo, recriar-se em suas singularidades. Na contemporaneidade, não existem indícios suficientes para afirmar que os conflitos futuros serão, exclusivamente, estabelecidos entre grupos ou nações de culturas distintas.

Em consequência disso, o risco do choque de civilizações é uma das possibilidades que se predispõem na atual recomposição da ordem mundial. Muitos dos conflitos que emergem com expressividade, no entanto, continuam a ocorrer no interior de uma mesma civilização em virtude de diferenças étnicas, como é o caso das disputas dos mundos árabe e africano. Esses conflitos são, portanto, uma realidade incontestável. De acordo com Hobsbawm (2007, p. 79-80), desde o pós-guerra fria o mundo vive em "uma era em que os conflitos armados, incontroláveis ou quase incontroláveis, tornaram-se endêmicos em grandes áreas da Ásia, da África, da Europa e em partes do Pacífico" e, além disso, "volta a ocorrer massacres em nível de genocídio e expulsões em massa de populações ('limpezas étnicas')", em escalas que já não eram vistas desde a Segunda Guerra Mundial.

Como já lembrava Winston Churchill em outro contexto, as disputas entre continentes, países e culturas, mesmo após as grandes guerras mundiais, "vão, sem dúvida, sempre continuar a existir" (2017, p. 1.154). Então, diante de uma série de contingências presentes em um ambiente compreendido como altamente complexo e perigoso, o uso difuso da violência em relação aos membros da mesma espécie traz à tona a irracionalidade sanguinária do único primata racional e autoconsciente: o homo sapiens. É justamente na hipótese da morte que se fixam as raízes da intensificação do medo e da insegurança presentes no contexto da sociabilidade humana (ZOLO, 2011, p. 89).

Essas sensações permanentes e prolixas são as principais características da sociedade de risco global, em que o medo retroalimenta-se por meio das intermináveis novas formas de ameaça e violência geopolítica que podem se concretizar em qualquer lugar do mundo, independentemente do contexto. Ao longo do percurso histórico-social, verifica-se que as expectativas em relação à consolidação de um mundo único e pacífico aparecem sempre ao final dos grandes conflitos, mas as inúmeras formas de violência entre os Estados e os grupos civilizacionais distintos carregam consigo um potencial que dificulta a união e a cooperação total entre as nações do globo, tornando ainda "mais distante o sonho de uma cidadania verdadeiramente universal" (SANTOS, 2017, p. 19). 
Em muitos países - como Sri Lanka, Caxemira, Colômbia, Ruanda, Camboja, Kosovo w Sérvia - o poder armado dos governos estatais tem se mostrado plenamente insuficiente para conter a explosão de conflitos étnico-religiosos ou de guerras civis, bem como para manter o controle dos seus territórios diante dos inúmeros desafios que se impõem socialmente. O que se evidencia, na verdade, é uma crise generalizada do poder e da legitimidade estatal. Tal fato pode ser constatado, inclusive, nos territórios de antigas e estáveis nações europeias, a exemplo da Espanha e do Reino Unido. Em 1993 estimava-se que estavam em curso cerca de 48 guerras étnicas pelo mundo afora e que existiam, aproximadamente, 164 conflitos étnico-territoriais em relação às fronteiras da ex-União das Repúblicas Socialistas Soviéticas (HOBSBAWM, 2007, p. 84).

Diante dessas circunstâncias conflitivas, não existem quaisquer perspectivas para a concretização de uma hegemonia imperial global por parte de um único Estado nacional, como pretendia os Estados Unidos, independentemente da maestria de sua força militar. Isso significa que a era dos grandes impérios já terminou e, portanto, a humanidade precisará encontrar outras maneiras e mecanismos capazes de gerir a organização da atual sociedade globalizada (HOBSBAWM, 2007, p. 84-85; HUNTINGTON, 2010, p. 45). Nesse caso em específico, é verificável que o componente político e as diretrizes governamentais dos Estados nacionais constituem-se fatores de ampla importância para a integração entre os povos e para a solução das inúmeras crises hostis que se instituem entre as mais variadas culturas, até porque as principais desigualdades "em desenvolvimento político e econômico entre as civilizações estão nitidamente enraizadas em suas culturas diferentes" (HUNTINGTON, 2010, p. 32).

Fato é que a dialética das relações existentes entre a globalização, as identidades nacionais, as xenofobias e os fundamentalismos religiosos, refletem no avanço dos cataclismos sociais e, inclusive, na desintegração moral do fim do século 20. Os grandes movimentos populacionais e os encontros culturais de civilizações distintas podem ser naturalmente explosivos, em especial, conforme aponta Hobsbawm (2007, p. 92), nos "países e regiões étnica, confessional e culturalmente homogêneos e desacostumados a grandes influxos de estrangeiros". Mesmo que a humanidade esteja seguindo em direção a uma história unificada, as identidades culturais que se configuram no seio das múltiplas civilizações jamais serão superadas mundialmente. Isso se deve ao fato de que a homogeneização das culturas se constitui como algo plenamente impossível na contemporaneidade e, por conseguinte, faz-se necessário deixar de pensar na possibilidade de construir uma sociedade plenamente integrada.

Por fim, torna-se urgente a ampliação das reflexões acerca das ideologias que visam o respeito, a inclusão e a proteção internacional dos direitos humanos às pluralidades culturais, compostas por diferentes cores, raças, etnias e religiões. Apesar das incertezas (BECK, 2011), no entanto, não se pode afirmar que o mundo está totalmente desprovido de ordem. Por isso, seria anacrônico crer que o passado não retroalimenta o presente, sugerindo um novo horizonte, afinal, como muito bem lembra Eric Hobsbawm (1995, p. 26), não se sabe "o que moldará o futuro, embora não se tenha resistido à tentação de refletir sobre os problemas, na medida em que eles surgem dos escombros do período que acaba de chegar ao fim", o que se espera é que a sociabilidade humana seja plenamente capaz de construir um "mundo melhor, mais justo e mais viável" - fortalecendo, para tanto, no novo milênio, as propostas teóricas em defesa dos direitos e garantias fundamentais inerentes a toda humanidade - uma vez que, em relação a isso, "o velho século [XX] não acabou bem".

\section{CONCLUSÃO}

A presente pesquisa preocupou-se em analisar a configuração política do mundo a partir da emergência do fenômeno da globalização e suas implicações para a aproximação das culturas e para os conflitos que esse processo estabelece. Em relação aos novos contornos estabelecidos pelo processo da globalização, emerge a necessidade de se encontrar formas eficazes para solucionar os conflitos e os riscos que passam a integrar o tecido social. Isso porque as respostas tradicionais, de cunho nacional, já não são mais suficientes para tal fim e, portanto, precisam ser reformuladas sob o viés do respeito às pluralidades e aos direitos humanos. Partindo desses aspectos, foram bordados os efeitos da potencialização dos riscos em um cenário repleto de medos, inseguranças e incertezas, em especial a possibilidade da emergência de um choque de civilizações.

Perante os anseios das civilizações no mundo contemporâneo, de culturas e identidades plurais, torna-se bastante difícil a consolidação de uma sociedade internacional pacífica e coesa, que garanta para toda a humanidade os direitos e garantias fundamentais. Nesse sentido, a proposta deste artigo apostou em abordar as in- 
terseções da sociedade de risco e a interdependência multicultural que se predispõe no seio da sociabilidade humana. Buscou-se, então, destacar a reconfiguração da ordem global no pós-Segunda Guerra Mundial e, em especial, depois do conflito bipolar Leste/Oeste da Guerra Fria, incorporando a tentativa de homogeneização e de estabelecimento de um império mundial por parte da maior potência econômico-militar da época: os Estados Unidos da América. Essa pretensão audaciosa tornou-se plenamente inviável, haja vista que surgiram outras potências estatais nas mais distintas áreas do mundo, fato que consolidou uma nova etapa: a multipolar.

No bojo do novo mundo que se configurou, as relações de interdependência intensificaram-se à medida que o modelo de Estados soberanos se relativizou em razão da possibilidade de transponibilidade das fronteiras. Por outro lado, a globalização contribuiu para a redução das distâncias e para a aproximação dos povos, o que ressaltou as heterogeneidades e fez emergir conflitos nos encontros de indivíduos de culturas distintas. Em outras palavras, pode-se afirmar que do choque de civilizações multiculturais deriva-se um conjunto de riscos e divergências que desafiam a contemporaneidade, uma vez que as culturas já não estão mais restritas aos territórios estatais; pelo contrário, elas ultrapassam as fronteiras das nações, ampliando as tensões, as lutas pela sobrevivência e, consequentemente, a afirmação de particularismos contra-hegemônicos.

O certo é que os processos que conectam as mais variadas culturas, pessoas e localidades se transnacionalizam e, por conseguinte, modificam o cotidiano da vida em sociedade. Em uma conjuntura assim estabelecida, reforça-se a necessidade de que a comunidade internacional precisa adotar políticas sociais capazes de solucionar pacificamente os conflitos, de gerir as estranhezas contrastantes provocadas por uma mescla de fatores complexos e de proteger universalmente os direitos inerentes a todos os seres humanos. Por fim, a cooperação entre as nações evidencia-se como um fator urgente para o estabelecimento de ações coordenadas aptas a evitar os choques de civilizações, de atender as exigências multiculturais e os anseios pelo fortalecimento dos direitos humanos e do respeito às heterogeneidades da sociedade de risco globalizada. Assim, sob o prisma do Direito Internacional dos Direitos Humanos, esta pesquisa conclui que a convivência pacífica entre os povos torna-se possível mediante a criação de políticas sociais que visam o respeito, a inclusão, o diálogo e a proteção dos direitos humanos às pluralidades culturais.

\section{REFERÊNCIAS}

APPADURAI, Arjun. Disjuncture and Difference in the Global Cultural Economy. In: Theory, Culture \& Society, London: SAGE Publications, vol. 7, n. 1, jun. p. 295-310, 1990. Available from: http://www.arjunappadurai.org/articles/Appadurai_Disjuncture_and_Difference_in_the_Global_Cultural_Economy.pdf. Cited: 27 jul. 2019.

BAUMAN, Zygmunt. Globalização: as consequências humanas. Tradução Marcus Penchel. Rio de Janeiro: Zahar, 1999.

BAUMAN, Zygmunt. Medo líquido. Tradução Carlos Alberto Medeiros. Rio de Janeiro: Zahar, 2008.

BAUMAN, Zygmunt; MAURO, Ezio. Babel: entre a incerteza e a esperança. Tradução Renato Aguiar. Rio de Janeiro: Zahar, 2016. BECK, Ulrich. O que é globalização? Equívocos do globalismo: respostas à globalização. Tradução André Carone. São Paulo: Paz e Terra, 1999.

BECK, Ulrich. Liberdade ou capitalismo. Ulrich Beck conversa com Johannes Willms. Tradução Luiz Antônio Oliveira de Araújo. São Paulo: Unesp, 2003.

BECK, Ulrich. Sociedade de risco: rumo a uma outra modernidade. Tradução Sebastião Nascimento. São Paulo: Editora 34, 2011.

BECK, Ulrich. Sociedade de risco mundial: em busca da segurança perdida. Tradução Marian Toldy e Teresa Toldy. Lisboa: Edições 70, 2016.

CASSIOLATO, José Eduardo. As políticas de ciência, tecnologia e inovação na China. In: Boletim de Economia e Política Internacional. Governo federal: repositório do conhecimento do Instituto de Pesquisa Econômica Aplicada (RCIpea). 2013. p. 65-80. Disponível em: http://repositorio.ipea.gov.br/handle/11058/3928. Acesso em: 26 jul. 2019.

CHURCHILL, Winston. Memórias da Segunda Guerra Mundial. Volume 1 (1919-1941) e Volume 2 (1941-1945). Tradução Vera Ribeiro. Rio de Janeiro: HarperCollins, 2017.

FARIA, José Eduardo. O direito na economia globalizada. São Paulo: Malheiros Ed., 2002.

GIDDENS, Anthony. Sociologia. 4. ed. Porto Alegre: Artmed, 2005.

HEGEL, Georg W. Friedrich. Introdução à história da filosofia. São Paulo: Redeel, 2005.

HOBSBAWM, Eric. Era dos extremos: o breve século XX - 1914-1991. Tradução Marcos Santarrita. São Paulo: Companhia das Letras, 1995. 
HOBSBAWM, Eric. Globalização, democracia e terrorismo. Tradução José Viegas. São Paulo: Companhia das Letras, 2007. HUNTINGTON, Samuel P. O choque de civilizações e a recomposição da ordem mundial. Tradução M. H. C. Côrtes. Rio de Janeiro: Objetiva, 2010.

IANNI, Octavio. A sociedade global. Rio de Janeiro: Civilização Brasileira, 2002.

IANNI, Octavio. Teorias da globalização. Rio de Janeiro: Civilização Brasileira, 2013.

IANNI, Octavio. A era do globalismo. Rio de Janeiro: Civilização Brasileira, 2014.

ITAMARATY. BRICS - Brasil, Rússia, Índia, China e África do Sul. Brasília: Itamaraty - Ministério das Relações Exteriores, 2019. Disponível em: http://www.itamaraty.gov.br/pt-BR/politica-externa/mecanismos-inter-regionais/3672-brics. Acesso em: 28 jul. 2019.

LUCAS, Doglas Cesar. Direitos humanos e interculturalidade: um diálogo entre a igualdade e a diferença. Ijuí: Editora Unijuí, 2013.

MARX, Karl. Contribuição à crítica da economia política. Tradução Florestan Fernandes. São Paulo: Expressão Popular, 2008.

MEIRELLES, Jose Gabriel Porcile; PEREIRA, Wellington. A ascensão da China na economia mundial: efeitos sobre o Brasil e América Latina. In: Revista Economia \& Tecnologia (RET), Curitiba: UFPR, vol. 4, n. 1, p. 19-18, jan./mar. 2008. Disponível em: http:// dx.doi.org/10.5380/ret.v4i1.27452. Acesso em: 27 jul. 2019.

SANTOS, Milton. Por uma outra globalização: do pensamento único à consciência universal. Rio de Janeiro: Record, 2017.

SANTOS JUNIOR, Raimundo Batista dos. A globalização ou o mito do fim do Estado. ljuí: Editora Unijuí, 2007.

SASSEN, Saskia. Sociologia da globalização. Tradução Ronaldo Cataldo Costa. Porto Alegre: Artmed, 2010.

WEBER, Max. A ética protestante e o espírito do capitalismo. Tradução Mário Moraes. São Paulo: Martin Claret, 2013.

ZOLO, Danilo. Rumo ao Ocaso Global? Os direitos humanos, o medo, a guerra. Org. Maria Luiza A. Feitosa e Giuseppe Tosi. São Paulo: Conceito Editorial, 2011. 